\title{
Extent of participation of women farmers and their problems in rice production in Assam
}

\author{
Pompi Saikia, Manoshi Baruah Deka and Manju Dutta Das
}

Received: 14.06.2018; Revised: 30.10.2018; Accepted: 14.11.2018

See end of the paper for authors' affiliations Pompi Saikia Department of Extension and Communication Management, Faculty of Home Science, Assam Agricultural University, Jorhat (Assam) India

Email : pompisaikia.aau@ gmail.com
ABSTRACT : This study examined the level of participation of women farmers in rice production in Jorhat district of Assam. Data for the study were obtained from 200 respondents and summarized using frequency distribution, percentages and correlation. Our analysis reveals that in rice cultivation all the activities except weeding and ploughing is dominated by women in the sample area. Majority of the rural women were involved independently in activities like processing $(62.25 \%)$, transplanting $(57.75 \%)$, cleaning $(55.50 \%)$, drying $(54.25 \%)$ and winnowing (52.00\%). Though their participation in different rice production activities were high but rural women faced various problems in production of rice crop and decision making. This study however recommends that government should facilitate the availability of credit facilities, inputs and infrastructural facilities and also revitalize and encourage ago-based industries so as to improve the efficiency in processing and marketing of rice products.

KEY WORDS: Participation, Women farmers, Rice production, Problems, Decision making

- HOW TO CITE THIS PAPER : Saikia, Pompi, Deka, Manoshi Baruah and Das, Manju Dutta (2018). Extent of participation of women farmers and their problems in rice production in Assam. Asian J. Home Sci., 13 (2) : 579-584, DOI: 10.15740/HAS/AJHS/13.2/579-584. Copyright@ 2018: Hind Agri-Horticultural Society. 